\title{
Interpreting the cloud cover - aerosol optical depth relationship found in satellite data using a general circulation model
}

\author{
J. Quaas ${ }^{1}$, B. Stevens ${ }^{2}$, P. Stier ${ }^{2}$, and U. Lohmann ${ }^{3}$ \\ ${ }^{1}$ Max Planck Institute for Meteorology, Hamburg, Germany \\ ${ }^{2}$ Atmospheric, Oceanic and Planetary Physics, University of Oxford, UK \\ ${ }^{3}$ Institute for Atmospheric and Climate Science/ETH Zurich, Switzerland
}

Received: 27 September 2009 - Published in Atmos. Chem. Phys. Discuss.: 4 December 2009

Revised: 28 May 2010 - Accepted: 4 July 2010 - Published: 7 July 2010

\begin{abstract}
Statistical analysis of satellite data shows a positive correlation between aerosol optical depth (AOD) and total cloud cover (TCC). Reasons for this relationship have been disputed in recent literature. The aim of this study is to explore how different processes contribute to one model's analog of the positive correlation between aerosol optical depth and total cloud cover seen in the satellite retrievals. We compare the slope of the linear regression between the logarithm of TCC and the logarithm of AOD, or the strength of the relationship, as derived from three satellite data sets to the ones simulated by a global aerosol-climate model. We analyse model results from two different simulations with and without a parameterisation of aerosol indirect effects, and using dry compared to humidified AOD. Perhaps not surprisingly we find that no single one of the hypotheses discussed in the literature is able to uniquely explain the positive relationship. However the dominant contribution to the model's AOD-TCC relationship can be attributed to aerosol swelling in regions where humidity is high and clouds are coincidentally found. This finding leads us to hypothesise that much of the AOD-TCC relationship seen in the satellite data is also carried by such a process, rather than the direct effects of the aerosols on the cloud fields themselves.
\end{abstract}

\section{Introduction}

Aerosols can impact clouds by serving as cloud condensation nuclei $(\mathrm{CCN})$. Since some aerosols and aerosol precursor gases are emitted by anthropogenic activities, this implies an anthropogenic perturbation of the climate system (Lohmann

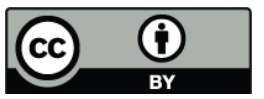

Correspondence to: J. Quaas

(johannes.quaas@zmaw.de) and Feichter, 2005; IPCC, 2007). At higher aerosol concentrations, cloud droplet number concentration (CDNC) is generally increased, which leads to increased cloud albedo for constant liquid water path (Twomey, 1974). Cloud microphysics and dynamics may also respond to changes in aerosol concentration. It has been postulated that when droplet sizes are reduced due to increased CDNC, precipitation formation processes might be delayed, so that cloud lifetime and subsequently total cloud cover (TCC) is increased (Albrecht, 1989).

Satellite data show a positive correlation between TCC and aerosol optical depth (AOD), a measure of vertically integrated light extinction by aerosol (Sekiguchi et al., 2003; Loeb and Manalo-Smith, 2005; Kaufman et al., 2005a; Kaufman and Koren, 2006; Matheson et al., 2006; Myhre et al., 2007; Menon et al., 2008; Quaas et al., 2008). There is a large discussion in the recent literature about the causes for this relationship. Interpreting this relationship, it has been suggested that global annual mean cloud cover increased by $3 \%$ due to anthropogenic aerosol (Kaufman and Koren, 2006). Such an effect would introduce a very large radiative forcing, which would almost be sufficient to balance the forcing by a doubling in $\mathrm{CO}_{2}$ concentration (Slingo, 1990).

However, it is largely debated in the recent literature whether the satellite-derived TCC - AOD relationship is due to the aerosol cloud lifetime effect, or whether it could be explained by other reasons (Stevens and Feingold, 2009). Six main hypotheses for such relationships have been advanced:

1. Cloud lifetime effect: Aerosols act as $\mathrm{CCN}$ increasing CDNC and decreasing droplet size. This may delay precipitation formation and may subsequently increase cloud lifetime and TCC (Albrecht, 1989; Kaufman and Koren, 2006). The TCC-AOD relationship is explained

Published by Copernicus Publications on behalf of the European Geosciences Union. 
as causality with aerosols influencing TCC through microphysical processes.

2. Meteorological co-variation: In meteorological situations such as large-scale convergence, increased aerosol number concentrations occur at the same time and location as larger TCC (Mauger and Norris, 2007; Loeb and Schuster, 2008).

3. Aerosol swelling: Aerosol size increases in the air surrounding clouds where relative humidity is higher (Haywood et al., 1997; Charlson et al., 2007; Koren et al., 2007; Myhre et al., 2007; Twohy et al., 2009; Roelofs et al., 2010). In contrast to hypothesis 2, the actual aerosol number concentration is not increased, but just the AOD, the metric used to quantify it, is larger.

4. Satellite retrieval errors: Scattering of sunlight at sides of clouds with complex shapes increases reflected radiation in the vicinity of clouds, which results in a highbias in the retrieved AOD near clouds (" 3 -D radiation bias"; Loeb and Manalo-Smith, 2005; Wen et al., 2007; Várnai and Marshak, 2009). Also, spurious clouds might be un-detected by the retrieval algorithm in regions identified as clear and thus used for an AOD retrieval ("cloud contamination"; Kaufman et al., 2005b; Zhang et al., 2005; Tian et al., 2008). In both cases, AOD is high-biased in the vicinity of clouds. However, airborne high-spectral resolution lidar data, unbiased by such artifacts, also show an increase in aerosol scattering in the vicinity of clouds ( $\mathrm{Su}$ et al., 2008), as do spaceborne lidar data (Tackett and Di Girolamo, 2009).

5. Cloud processing or in-cloud nucleation of aerosols: Inside cloud droplets, aqueous sulfur chemical reactions lead to sulfate formation. This process together with collision-coalescence processes support the growth of embedded CCN upon the evaporation of cloud droplets, potentially enhancing AOD (e.g., Feichter et al., 1996; Su et al., 2008)

6. Wet scavenging: Wet scavenging of aerosol by precipitation formed in clouds, the predominant sink of $\mathrm{CCN}$, would introduce a relationship between AOD and cloud cover, which, however, presumably would be negative.

In the present study, we examine the relative importance of these hypotheses as far as possible with the help of general circulation model (GCM) sensitivity studies. Clearly a GCM is an imperfect tool for such an investigation (see e.g., Stevens and Feingold 2009 for a critical review), particularly to the extent one relies on its representation of parameterised processes. However, a GCM does reasonably represent the large-scale patterns of meteorological variability and the spatial distribution of different types of aerosol. Hence it is interesting to ask to what extent its analog of the AOD-TCC relationship apparent in the satellite data can be attributed to large-scale effects which the GCM can be expected to well represent (e.g., hypotheses 2 and 3) versus small scale effects where the results of the GCM are more questionable (hypotheses 1,5 and 6), versus effects that do not yet even arise in GCMs (hypothesis 4).

\section{Methods}

The satellite data used here are from the MODerate Resolution Imaging Spectroradiometer (MODIS; Minnis et al., 2003; Remer et al., 2005) on board the Terra and Aqua satellites, as obtained from the Clouds and the Earth's Radiant Energy System (CERES; Wielicki et al., 1996) SSF Edition 2 datasets. Terra data, valid for about 10:30 a.m. local time, cover the January 2001-December 2007 period, and Aqua data, with 01:30 p.m. local overpass time, the January 2004December 2006 period. Also used are data from the AlongTrack Scanning Radiometer (ATSR-2) on board the ERS-2 satellite with an equator-crossing local time of about 10.30 a.m. from the Oxford-RAL Aerosols and Clouds (ORAC) Global Retrieval of ATSR Cloud Parameters and Evaluation (GRAPE; version 3; Thomas et al., 2009; Poulsen et al., 2009) for the January 1996-December 1999 period. It should be noted that the MODIS retrievals are done at a $10 \times 10 \mathrm{~km}^{2}$ grid, while the ATSR-2 retrievals are performed at a somewhat higher resolution of $3 \times 4 \mathrm{~km}^{2}$. Fractional cloud cover is determined as the number of pixels of $1 \times 1 \mathrm{~km}^{2}$ scale identified by cloud detection tests in different spectral channels (Minnis et al., 2003) as cloudy, divided by the total number of pixels in each grid-box (here at T63 horizontal resolution). Aerosol optical depth is retrieved in pixels identified as cloud free at a scale of $10 \times 10 \mathrm{~km}^{2}$ (Remer et al., 2005). For more details, the reader is referred to the algorithm descriptions by Kaufman et al. (1997) and Tanré et al. (1997).

The atmospheric GCM used is the ECHAM5 model (Roeckner et al., 2003), coupled to the modal aerosol scheme HAM considering sea salt, dust, sulfate, black carbon and organic carbon in seven internally mixed hydrophilic or hydrophobic log-normal modes with fixed variance, including aerosol microphysical interactions (Stier et al., 2005). The model is run at T63L31 resolution for one year with prescribed monthly-mean AMIP2 sea surface temperature and sea-ice cover distributions for AD 2000, with aerosol and aerosol precursor emissions from the AEROCOM dataset valid for the year AD 2000 (Dentener et al., 2006). Aerosol optical depth is computed in the model in a way consistent with the satellite retrievals. For each of the seven lognormal modes the model calculates the complex volumeweighted mean refractive index considering all aerosol components, including thermodynamically calculated aerosol water, which serve together with the median radius as input to look-up tables from off-line Mie radiative transfer calculations. The calculations are performed on 24 wavelengths including the presented results valid for a wavelength 
of 550nm. The water content for each mode is calculated from the internally mixed aerosol concentrations based on the ZSR- Relation (Zadanovskii, 1948; Stokes and Robinson, 1966) using binary molality coefficients from Jacobson et al. (1996). The derived equilibrium composition, including aerosol water, is used to calculate ambient median radii for each of the modes, which in turn serve as input to the aerosol radiation scheme (as well as to all other microphysical processes). The cloud cover and large-scale condensation are diagnosed from a prognostic subgrid-scale distribution of total water mixing ratio (Tompkins, 2002). In this scheme, variance and skewness of the total water mixing ratio are computed as a function of atmospheric processes. Parts of the PDF which are super-saturated given the grid-box mean temperature are considered cloudy, and the total water mixing ratio in excess of saturation condenses. This scheme produces a realistic distribution of cloud cover (Tompkins, 2002). In this scheme, cloud cover is not prognostic. Nevertheless, due to its flexibility, the scheme is likely to be relatively sensitive in terms of cloud cover to perturbations as, e.g., by the second aerosol indirect effect (Lohmann and Feichter, 1997; Lohmann et al., 2007). ECHAM5 includes two different choices for cloud microphysical schemes. The standard single-moment cloud scheme treats liquid and ice water mixing ratio as prognostic variables, but holds cloud droplet and ice particle number concentrations fixed and thus does not consider aerosol influences on cloud microphysics (Lohmann and Roeckner, 1996). The optional double-moment liquid and ice-cloud microphysical scheme (Lohmann et al., 2007) parameterises droplet activation as a function of the number concentration of aerosols in the hydrophilic modes following the empirical formulation by Lin and Leaitch (1997), and applies the autoconversion parameterisation by Khairoutdinov and Kogan (2000) for precipitation formation, which depends on cloud droplet number concentration and thus some representation of the second aerosol indirect effect in the sense of a cloud lifetime effect. For model evaluation, the reader is referred to previous studies (e.g., Tompkins, 2002; Lohmann et al., 2007; Pincus et al., 2008; Reichler and Kim, 2008). In this study, two model integrations are done; one with the singlemoment cloud scheme (no aerosol indirect effects included) and one with the double-moment cloud scheme (all parameterised aerosol-cloud interactions included). The aerosols are computed interactively using the same scheme in both integrations.

Following Feingold et al. (2003), the strength of the aerosol-cloud cover relationship is quantified here as the slope of the linear regression between the natural logarithm of TCC and the natural logarithm of AOD

$b=\Delta \ln \mathrm{TCC} / \Delta \ln \mathrm{AOD}$.

This quantity shows the relative change in TCC with a relative perturbation in AOD.

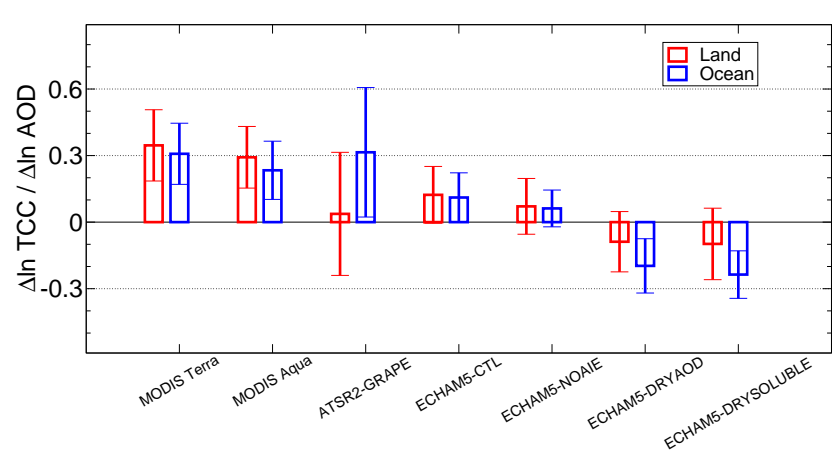

Fig. 1. Slope of the relationship $\ln$ TCC vs. $\ln$ AOD (see text for details). The weighted average for four seasons and all six land regions (red) and eight ocean regions (blue) is shown, with the variability as error bar. Error bars for the satellite data also include the inter-annual variability among the eight, three and four years, for MODIS Terra, MODIS Aqua, and ATSR2-GRAPE, respectively.

We compute the regressions for both, satellite data and GCM simulation results, in a consistent way, gridding the satellite data to the model grid, separately for fourteen different ocean and land regions and the four seasons as in Quaas et al. (2008). The geographical distribution of the regions is shown in Supplementary Fig. 1. Spatial scale plays an important role when computing statistical relationships. We assure comparability here by interpolating all data to the model's T63 horizontal grid (approx. $1.8^{\circ}$ resolution).

\section{Results and discussion}

Figure 1 shows the slopes of the regression between TCC and AOD as the weighted mean values for ocean and land areas for all seasons, with the error bars showing the variability among the regions and seasons as standard deviation. For the satellite datasets, the intra-annual variability is also included in the computation of the standard deviation shown in the error bars. All individual sensitivities are shown in Supplementary Fig. 2.

As previously reported, the MODIS data show a strongly positive relationship between TCC and AOD. There is no clear land-ocean contrast, and a substantial variability among the regions/seasons and even between the years (note that for MODIS on Terra, we had eight years of data available compared to only three for MODIS on Aqua). There is no distinct seasonal cycle in this strength, nor are differences between the hemispheres, or between tropics and extratropics evident. The most prominent feature is a land-ocean contrast with some land regions showing quite large, others smaller values than the more homogeneous oceanic regions. The ATSR2 dataset also shows a positive relationship. The ATSR2-derived slope is on average similar to the MODIS Terra slope over the oceans, but much smaller over land. ATSR2 shows much more variability, and the small value 
over land is dominated by negative correlations over Africa and Oceania (Supplementary Fig. 2c), where the influence of large dust loading, and related retrieval issues, may play a role.

ECHAM5-HAM in the control simulation shows relationship strengths smaller than in the satellite data (taken MODIS Terra as reference data) by about $50 \%$, of the order of 0.1 . In the second model study, the single-moment cloud microphysical scheme is used. In this scheme, aerosols do not influence cloud microphysics - aerosol indirect effects are switched off. This simulation "NOAIE" nevertheless shows a strongly positive relationship between TCC and AOD, with the slight land-ocean contrast virtually unchanged. However, the strength of the relationship is reduced. The amount by which the relationship is less strong in the simulation without the aerosol indirect effects compared to the control simulation might indicate the relative contribution of the simulated cloud lifetime effect to the positive relationship between TCC and AOD. However, this conclusion has to be treated with caution since the model versions are different (one- versus two-moment cloud microphysical scheme), and the parameterisation of the cloud lifetime effect just in terms of the autoconversion parameterisation, and the representation of clouds themselves are crude. Indeed, the cloud lifetime effect may be overestimated rather than underestimated by the model (Quaas et al., 2009). The result found here is consistent with the findings of Lohmann et al. (2006), who investigated the vertically resolved TCC for four bins of AOD over the tropical Atlantic ocean. A thorough evaluation of the microphysical processes and boundary layer dynamics would be needed to more comprehensively understand contributions of cloud lifetime effects to the TCC - AOD relationship, but this is beyond the scope of the present study.

We further analyse the results of the latter simulation (NOAIE) using two different ways to compute AOD. In one case, we use the dry masses of all aerosol species to compute the AOD ("DRYAOD"), and in a second case, only the dry mass concentrations of the aerosol species considered good cloud condensation nuclei ("DRYSOLUBLE"), namely sea salt, sulfate and organic carbon. The optical depth by aerosol components (dry aerosol species and aerosol water) is estimated from the total aerosol optical depth as the component volume fraction of the total AOD.

It is evident that in the ECHAM5-HAM model, the aerosol water uptake is responsible for much of the relationship between TCC and AOD. Indeed, when using the dry aerosol mass to compute the relationship, it becomes negative rather than positive. A negative relationship is what would be expected if the aerosol sink by wet scavenging was the dominant process which relates cloud cover and aerosol concentration. This negative relationship between TCC and AOD is virtually unchanged when the dry mass concentration only of potential CCN (soluble particles) is used. This suggests that the large dust concentrations in particularly dry areas, and thus a purely geographical correlation, is not the main factor by which the negative relationship between TCC and dry AOD is influenced. Moreover, the way aerosol humidification is computed in the model by using one clear-sky humidity value rather than a distribution which would steeply increase towards cloud edges would likely tend to underestimate the real effect. Hence, the correlation between TCC and AOD might in reality be even more strongly dominated than our results suggest. Because this is a relatively large scale effect, which principally depends on the ability of the GCM to well represent the covariability between aerosol type and airmass properties, it becomes plausible to hypothesise that a similar effect dominates the relationship between aerosol optical depth and total cloud cover seen in the satellite data.

\section{Summary and conclusions}

Reasons for the strongly positive relationship between total cloud cover (TCC) and aerosol optical depth (AOD) as found in satellite datasets are explored using sensitivity studies with a general circulation model (the ECHAM5 GCM) including the comprehensive aerosol module HAM and the choice for either a double- or a single moment cloud microphysical scheme. Six hypotheses have been identified in the literature which might explain the correlation between cloud cover and aerosols (see Introduction): (1) The cloud lifetime aerosol effect, (2) meteorological co-variation, (3) aerosol swelling in the humid environment where clouds form, (4) satellite retrieval errors, (5) in-cloud aerosol production and processing, and (6) aerosol wet scavenging, where the latter effect would produce a negative rather than positive relationship. All effects, except for satellite retrieval errors, are represented or parameterised in the model. Under the (most likely overly optimistic) assumption that these representations are correct, the extent to which the model shows a less strong relationship between TCC and AOD infers the amount by which satellite retrieval errors (hypothesis 4) are responsible for the positive relationship found in the satellite data. Because other lines of evidence (Quaas et al., 2009) suggest that the model over-emphasises aerosol indirect effects, the tendency of the MODIS data to yield a stronger AOD-TCC relationship than we find in the model suggests that retrieval biases are likely important. For a realistic quantification of the relative importance of retrieval errors, however, other methods need to be applied (e.g., Várnai and Marshak, 2009; 2010).

The model shows a somewhat smaller slope in the case where aerosol indirect effects are switched off. An interpretation could be that in the model, some part of the correlation between TCC and AOD is due to impacts of aerosols on cloud microphysics (hypothesis 1). However, the slight differences in the model versions and uncertainties in the parameterisation make it impossible to provide a more reliable assessment of this hypothesis.

A very strong signal is obtained when using AOD computed from the dry aerosol mass concentrations rather than 
humidified aerosol. The relationship between TCC and AOD turns strongly negative in this case. It is not a pure geographical co-variation as shown when using the dry AOD computed only from the soluble aerosol components. Rather, the wet scavenging of aerosol by precipitation formed in clouds is likely an important process determining this negative relationship. The difference in the relationship between TCC and humid AOD and TCC and dry AOD, respectively, clearly shows that the influence of high humidity in the vicinity of clouds causes a swelling of the existing aerosol increasing the AOD (hypothesis 3). In-cloud aerosol production and aerosol microphysical processing (hypothesis 5), as well as meteorological co-variation (hypothesis 2 ) are both included in this relationship. Comparing the results when using dry AOD from all vs. dry AOD from only soluble aerosol components in the model results in similar AOD-TCC relationships. This might imply that meteorological co-variation (hypothesis 2), which would be expected to show a particularly strong effect for the - initially after emission less soluble dust, and in-cloud aerosol production and aerosol microphysical processing (hypothesis 5), which would yield a particularly strong effect for the soluble-only case, are not the dominant reasons.

In agreement with findings by Myhre et al. (2007) and Twohy et al. (2009), our results suggest that the increase of aerosol optical depth that accompanies the swelling of aerosol particles in humid airmasses is the dominant process (process 3 in the above list) contributing to the observed strong correlation between TCC and AOD in remote sensing data. Although we can not rule out that real aerosol effects on clouds (process 1) or remote sensing errors (process 4) may also play a role, the inference from our analysis is that such processes may be secondary when it comes to explaining observed effects.

\section{Supplementary material related to this article is available online at: http://www.atmos-chem-phys.net/10/6129/2010/ acp-10-6129-2010-supplement.pdf.}

Acknowledgements. The MODIS data used in this study were acquired as part of NASA's Earth Science Enterprise. The MODIS Science Teams developed the retrieval algorithms. The authors would like to thank the data distribution center for its support. Computing time was provided by the German High Performance Computing Centre for Climate and Earth System Research (Deutsches Klimarechenzentrum, DKRZ). J. Q. was supported by an Emmy Noether grant of the German Research Foundation (DFG). We are grateful for comments on the manuscript by Irina Sandu and two anonymous reviewers.

Edited by: K. Lehtinen

\section{References}

Albrecht, B. A.: Aerosols, cloud microphysics, and fractional cloudiness, Science, 245, 1227-1230, 1989.

Charlson, R. J., Ackerman, A. S., Bender, F. A.-M., Anderson, T. L., and Liu, Z.: On the climate forcing consequences of the albedo continuum between cloudy and clear air, Tellus 59B, 715-727, 2007.

Dentener, F., S. Kinne, T. Bond, O. Boucher, J. Cofala, S. Generoso, P. Ginoux, S. Gong, J. Hoelzemann, A. Ito, L. Marelli, J. Penner, J.-P. Putaud, C. Textor, M. Schulz, G.v.d. Werf, and J. Wilson: Emissions of primary aerosol and precursor gases in the years 2000 and 1750 - prescribed data-sets for AeroCom, Atmos. Chem. Phys., 6, 4321-4344, doi:10.5194/acp-6-4321-2006, 2006.

Feichter, J., Kjellström, E., Rodhe, H., Dentener, F., Lelieveld, J., and Roelofs, G. J.: Simulation of the tropospheric sulfur cycle in a global climate model, Atmos. Environ., 30, 1693-1707, 1996.

Feingold, G., Eberhard, W. L., Veron, D. E., and Previdi, M.: First measurements of the Twomey indirect effect using ground-based remote sensors, Geophys. Res. Lett., 30(6), 1287, doi:10.1029/2002GL016633, 2003.

Haywood, J. M., Ramaswamy, V., and Donner, L. J.: A LimitedArea-Model Case Study of the Effects of Sub-Grid Scale Variations in Relative Humidity and Cloud Upon the Direct Radiative Forcing of Sulfate Aerosol, Geophys. Res. Lett., 24(2), 143-146, 1997.

IPCC: Climate change 2007 - The scientific basis. Contribution of working group I to the Fourth Assessment Report of the Intergovernmental Panel on Climate Change, Cambridge University Press, Cambridge, 2007.

Jacobson, M. Z., Tabazadeh, A., and Turco, R. P.: Simulating equilibrium within aerosols and nonequilibrium between gases and aerosols, J. Geophys. Res., 101, 9079-9091, 1996.

Kaufman Y. J., Tanré, D., Remer, L. A., Vermote, E., Chu, A., and Holben, B. N.: Operational remote sensing of tropospheric aerosol over land from EOS Moderate Resolution Imaging Spectroradiometer, J. Geophys. Res., 102, 17051-17067, 1997.

Kaufman, Y. J., Koren, I., Remer, L., Rosenfeld, D., and Rudich, I.: The effect of smoke, dust, and pollution aerosol on shallow cloud development over the Atlantic Ocean, Proc. Natl. Acad. Sci. 102, 11207-11212, 2005a.

Kaufman, Y. J., Remer, L. A., Tanre, D., Rong-Rong, L., Kleidman, R., Mattoo, S., Levy, R. C., Eck, T. F., Holben, B. N., Ichoku, C., Martins, J. V., and Koren, I.: A critical examination of the residual cloud contamination and diurnal sampling effects on MODIS estimates of aerosol over ocean, IEEE Transact. Geosci. Remote Sens., 43(12), 28862897, doi:10.1109/TGRS.2005.858430, 2005b.

Kaufman, Y. J. and I. Koren: Smoke and pollution aerosol effect on cloud cover, Science, 313, 655-658, doi:10.1126/science.1126232, 2006.

Khairoutdinov, M. and Kogan, Y.: A new cloud physics parameterization in a large-eddy simulation model of marine stratocumulus, Mon. Weather Rev., 128, 229-243, 2000.

Koren, I., Remer, L. A., Kaufman, Y. J., Rudich, Y., and J. V. Martins: On the twilight zone between clouds and aerosols, Geophys. Res. Lett., 34, L08805, doi:10.1029/2007GL029253, 2007.

Lin, H. and Leaitch, W. R.: Development of an in-cloud aerosol activation parameterization for climate modelling. Proceedings 
of the WMO Workshop on Measurement of Cloud Properties for Forecasts of Weather, Air Quality and Climate, Mexico City, June, 328-335, 1997.

Loeb, N. G. and Manalo-Smith, N.: Top-of-atmosphere direct radiative effect of aerosols over global oceans from merged CERES and MODIS observations, J. Clim., 18, 3506, 2005.

Loeb, N. G., and Schuster, G. L.: An observational study of the relationship between cloud, aerosol and meteorology in broken low-level cloud conditions, J. Geophys. Res., 113, D14214, doi:10.1029/2007JD009763, 2008.

Lohmann, U. and Roeckner, E.: Design and performance of a new cloud microphysics scheme developed for the ECHAM general circulation model, Clim. Dynam., 12, 557-572, 1996.

Lohmann, U. and Feichte, J.r: Impact of sulfate aerosols on albedo and lifetime of clouds: A sensitivity study with the ECHAM4 GCM, J. Geophys. Res., 102(D12), 13685-13700, 1997.

Lohmann, U. and Feichter, J.: Global indirect aerosol effects: A review, Atmos. Chem. Phys. 5, 715-737, 2005.

Lohmann, U., Koren, I., and Kaufman, Y. J.: Disentangling the role of microphysical and dynamical effects in determining cloud properties over the Atlantic, Geophys. Res. Lett., 33, L09802, doi:10.1029/2005GL024625, 2006.

Lohmann, U., Stier, P., Hoose, C., Ferrachat, S., Kloster, S., Roeckner, E., and Zhang, J.: Cloud microphysics and aerosol indirect effects in the global climate model ECHAM5-HAM, Atmos. Chem. Phys., 7, 3425-3446, doi:10.5194/acp-7-3425-2007, 2007.

Matheson, M. A., Coakley Jr., J. A., and Tahnk, W. R.: Multiyear Advanced Very High Resolution Radiometer observations of summertime stratocumulus collocated with aerosols in the northeastern Atlantic, J. Geophys. Res., 111, D15206, doi:10.1029/2005JD006890, 2006.

Mauger, G. S. and Norris, J. R.: Meteorological bias in satellite estimates of aerosol-cloud relationships, Geophys. Res. Lett., 34, L16824, doi:10.1029/2007GL029952, 2007.

Menon, S., Del Genio, A. D., Kaufman, Y. J., Bennartz, R., Koch, D., Loeb, N., and Orlikowski, D.: Analyzing signatures of aerosol-cloud interactions from satellite retrievals and the GISS GCM to constrain the aerosol indirect effect, J. Geophys. Res., 113, D14S22, doi:10.1029/2007JD009442, 2008.

Minnis, P., Sun-Mack, D. F., Heck, P. W., Doelling, D. R., and Trepte, Q. Z.: CERES cloud property retrievals from imagers on TRMM, Terra, and Aqua. Proc. SPIE $10^{\text {th }}$ International Symposium on Remote Sensing: Conference on Remote Sensing of Clouds and the Atmosphere VII, Barcelona, Spain, 8-12 September, 5235, 37-48, 2003.

Myhre, G., Stordal, F., Johnsrud, M., Kaufman, Y. J., Rosenfeld, D., Storelvmo, T., Kristjansson, J. E., Berntsen, T. K., Myhre, A., and Isaksen, I. S. A.: Aerosol-cloud interaction inferred from MODIS satellite data and global aerosol models, Atmos. Chem. Phys., 7, 3081-3101, doi:10.5194/acp-7-3081-2007, 2007.

Pincus, R., Batstone, C. P., Hofmann, R. J. P., Taylor, K. E., and Glecker, P. J.: Evaluating the present-day simulation of clouds, precipitation, and radiation in climate models, J. Geophys. Res., 113(D14), D14209, doi:10.1029/2007JD009334, 2008.

Poulsen, C. A., Campmany, E., Dean, S., Ewen, G., Sayer, A. M., Thomas, G. E., Grainger, R. G., Siddans, R., Lawrence, B., and Watts, P.: The ORAC ATSR-2 cloud retrieval algorithm for GRAPE, in preparation for the RSE AATSR special issue, 2009.
Quaas, J., Boucher, O., Bellouin, N., and Kinne, S.: Satellite-based estimate of the direct and indirect aerosol climate forcing, J. Geophys. Res., 113, D05204, doi:10.1029/2007JD008962, 2008.

Quaas, J., Ming, Y., Menon, S., Takemura, T., Wang, M., Penner, J. E., Gettelman, A., Lohmann, U., Bellouin, N., Boucher, O., Sayer, A. M., Thomas, G. E., McComiskey, A., Feingold, G., Hoose, C., Kristjánsson, J. E., Liu, X., Balkanski, Y., Donner, L. J., Ginoux, P. A., Stier, P., Grandey, B., Feichter, J., Sednev, I., Bauer, S. E., Koch, D., Grainger, R. G., Kirkevåg, A., Iversen, T., Seland, Ø., Easter, R., Ghan, S. J., Rasch, P. J., Morrison, H., Lamarque, J.-F., Iacono, M. J., Kinne, S., and Schulz, M.: Aerosol indirect effects - general circulation model intercomparison and evaluation with satellite data, Atmos. Chem. Phys., 9, 8697-8717, doi:10.5194/acp-9-8697-2009, 2009.

Reichler, T. and Kim, J.: How Well do Coupled Models Simulate Today's Climate?, Bull. Amer. Meteor. Soc., 89, 303-311, 2008.

Remer, L. A., Kaufman, Y. J., Tanré, D., Mattoo, S., Chu, D. A., Martins, J. V., Li, R. R., Ichoku, C., Levy, R. C., Kleidman, R. G., Eck, T. F., Vermote, E., and Holben, B. N.: The MODIS algorithm, products, and validation, J. Atmos. Sci., 62, 947-973, doi:10.1175/JAS3385.1, 2005.

Roeckner, E., Bäuml, G., Bonaventura, L., Brokopf, R., Esch, M., Giorgetta, M., Hagemann, S., Kirchner, I., Kornblueh, L., Manzini, E., Rhodin, A., Schlese, U., Schulzweida, U., and Tompkins, A.: The atmospheric general circulation model ECHAM5: Part I: Model description. Report No. 349, Max Planck Institute for Meteorology, Hamburg, Germany, 127 pp., 2003.

R Roelofs, G.-J., ten Brink, H., Kiendler-Scharr, A., de Leeuw, G., Mensah, A., Minikin, A., and Otjes, R.: Simulation of aerosol optical thickness during IMPACT (May 2008, The Netherlands) with ECHAM5-HAM, Atmos. Chem. Phys. Discuss., 10, 59115945, doi:10.5194/acpd-10-5911-2010, 2010.

Sekiguchi, M., Nakajima, T., Suzuki, K., Kawamoto, K., Higurashi, A., Rosenfeld, D., Sano, I., and Mukai, S.: A study of the direct and indirect effects of aerosols using global satellite data sets of aerosol and cloud parameters, J. Geophys. Res., 108(D22), 4699, doi:10.1029/2002JD003359, 2003.

Slingo, A.: Sensitivity of the Earth's radiation budget to changes in low clouds. Nature, 343, 49-51, 1990.

Stevens, B. and Feingold, G.: Untangling aerosol effects on clouds and precipitation in a buffered system, Nature, 461, 607-613, 2009.

Stier, P., Feichter, J., Kinne, S., Kloster, S., Vignati, E., Wilson, J., Ganzeveld, L., Tegen, I., Werner, M., Balkanski, Y., Schulz, M., Boucher, O., Minikin, A., and Petzold, A.: The aerosolclimate model ECHAM5-HAM, Atmos. Chem. Phys., 5, 11251156, doi:10.5194/acp-5-1125-2005, 2005.

Stokes, R. H. and Robinson, R. A.: Interactions in aqueous nonelectolyte solutions. I. Solute-solvent equilibria, J. Phys. Chem., 70, 2126-2130, 1966.

Su, W., Schuster, G. L., Loeb, N. G., Rogers, R. R., Ferrare, R. A., Hostetler, C. A., Hair, J. W., and Obland, M. D.: Aerosol and cloud interaction observed from high spectral resolution lidar data, J. Geophys. Res., 113, D24202, doi:10.1029/2008JD010588, 2008.

Tackett, J. L. and Di Girolamo, L.: Enhanced aerosol backscatter adjacent to tropical trade wind clouds revealed by satellite-based lidar, Geophys. Res. Lett., 36, L14804, 
doi:10.1029/2009GL039264, 2009.

Tanré D., Kaufman, Y. J., Herman, M., and Mattoo, S.: Remote sensing of aerosol properties over oceans using the MODIS/EOS spectral radiances, J. Geophys. Res., 102, 16971-16988, 1997.

Thomas, G. E., C. A. Poulsen, A. M. Sayer, S. H. Marsh, S. M. Dean, E. Carboni, R. Siddans, R. G. Grainger, and B. N. Lawrence: The ORAC ATSR-2 aerosol retrieval algorithm for GRAPE, Atmos. Meas. Tech., submitted, 2009.

Tian, B., Waliser, D. E., Kahn, R. A., Li, Q., Yung, Y. L., Tyranowski, T., Geogdzhayev, I. V., Mishchenko, M. I., Torres, O., and Smirnov, A.: Does the Madden-Julian Oscillation influence aerosol variability?, J. Geophys. Res., 113, D12215, doi:10.1029/2007JD009372, 2008.

Tompkins, A.: A prognostic parameterization for the subgrid-scale variability of water vapor and clouds in largescale models and its use to diagnose cloud cover, J. Atmos. Sci., 59, 1917-1942, 2002.

Twohy, C. H., Coakley Jr., J. A., and Tahnk, W. R.: Effect of changes in relative humidity on aerosol scattering near clouds, J. Geophys. Res., 114, D05205, doi:10.1029/2008JD010991, 2009.

Twomey, S.: Pollution and the planetary albedo, Atmos. Environ., 8, 1251-1256, 1974.
Várnai, T. and Marshak, A.: MODIS observations of enhanced clear-sky reflectance near clouds, Geophys. Res. Lett., 36, L06807, doi:10.1029/2008GL037089, 2009.

Várnai, T. and Marshak, A.: Global CALIPSO observations of aerosol changes near clouds. IEEE Rem. Sens. Lett., in press, 2010.

Wen, G., Marshak, A., Cahalan, R. F., Remer, L. A., and Kleidman, R. G.: 3-D aerosol-cloud radiative interaction observed in collocated MODIS and ASTER images of cumulus cloud fields, J. Geophys. Res., 112, D13204, doi:10.1029/2006JD008267, 2007.

Wielicki, B. A., Barkstrom, B. R., Harrison, E. F., Lee III, R. B., Smith, G. L., and Cooper, J. E.: Clouds and the Earth's Radiant Energy System (CERES): An earth observing system experiment. Bull. Am. Meteor. Soc. 77, 853-868, 1996.

Zhang, J., Reid, J. S., and Holben, B. N.: An analysis of potential cloud artifacts in MODIS over ocean aerosol optical thickness products, Geophys. Res. Lett., 32, L15803, doi:10.1029/2005GL023254, 2005.

Zadanovskii, A. B.: New methods for calculating solubilities of electrolytes in multicomponent systems, Zhur. Fiz. Kim., 22, 1475-1485, 1948. 